\title{
ANALISIS EFISIENSI TATANIAGA BAHAN OLAH KARET (BOKAR) DI DESA SUMBU SARI KECAMATAN MESUJI RAYA KABUPATEN OGAN KOMERING ILIR PROPINSI SUMATERA SELATAN
}

\author{
${ }^{1}$ Sri Rahayu Endang Lestari, SP, M.Si \\ ${ }^{1}$ Program Studi Agribisnis Jurusan Sosial Ekonomi Fakultas Pertanian \\ Universitas Tridinanti Palemban, Sumatera Selatan \\ 1lestarimuhammad@yahoo.com
}

\begin{abstract}
Sri Rahayu Endang Lestari. Efficiency Analysis of Rubber Sports Materials (Bokar) in Sumbu Sari Village, Mesuji Raya District, Ogan Komering Ilir Regency. This study aims to find out how the channels of community rubber trading in Sumbu Sari Village, Mesuji Raya District, Ogan Komering Ilir Regency, and calculating how much the level of trading efficiency of rubber processing materials (bokar) in Sumbu Sari Village is seen from the trading margin, the trading advantages and the share received by the farmers. This research was carried out in August 2018.

The sampling method in this study is the sampling method used is simple random (Random sampling). Sampling was carried out on rubber farmers whose rubber plants were around 10 to 15 years old with an average land area of 2 ha and a population of 100 heads of rubber farmers in Sumbu Sari Village. While the sample was taken 20 percent, the number of farmers sampled was 20 rubber farmers as respondents.

The results of this study indicate that there is a trading channel that involves two intermediary institutions, namely wholesalers and factories / exporters (PT. Hevea MK II) as the final consumers in the Rubber Material Material Trading Channel (BOKAR) in Sumbu Sari Village, Mesuji Raya District, Ogan Regency. Komering Ilir and the level of efficiency of the trading system for Rubber Sports Materials (BOKAR) which is 33.28\% (efficient) with the farmer's share of the trade of $57.14 \%$ and the total trading margin of Rp. 6,000 contained in the trading channel in Sumbu Sari Village, Mesuji Raya District, Ogan Komering Ilir Regency. This shows that short trading channels are more efficient than long trading channels.
\end{abstract}

Key words : efficiency, Bokar, rubber 


\section{PENDAHULUAN}

\section{A. Latar Belakang}

Potensi ekonomi yang menjadi andalan utama di Kabupaten Ogan Komering Ilir adalah sektor pertanian dan perkebunan. Hal ini terlihat dari PDRB Kabupaten Ogan Komering Ilir, sektor pertanian masih tetap merupakan sektor dominan dalam pembentukan PDRB Kabupaten Ogan Komering Ilir dengan sebesar 43,28 persen dari total PDRB daerah ini pada tahun 2014 (BPS Kabupaten Ogan Komering Ilir, 2014).

Kecamatan Mesuji Raya adalah sebuah Kecamatan di Kabupaten Ogan Komering Ilir, Provinsi Sumatra Selatan, Kecamatan Mesuji Raya di bentuk Pada tahun 2005, Desa di Kecamatan Mesuji Raya penduduknya mayoritas transmigrasi saat kepemimpinan presiden yang kedua, sekitar tahun 1980-an, masyarakatnya terdiri dari berbagai daerah yang ada di pulau jawa. Salah satu Desa di Kecamatan ini adalah Desa Sumbu Sari, Dimana desa ini memiliki areal perkebunan karet yang cukup luas yaitu 961 hektar dari total 3.435 hektar perkebunan karet yang ada di Kecamatan Mesuji Raya Kabupaten Ogan Komering Ilir (Dinas Perkebunan Kecamatan Mesuji Raya, 2015).

Tataniaga bokar ke pabrik dilakukan petani melalui pedagang pengumpul yang ada di Desa Sumbu Sari. Pada umumnya tataniaga bokar oleh petani banyak dilakukan melalui lembaga Tataniaga yang ada senantiasa merugikan para petani karena rendahnya harga yang ditetapkan pedagang. Karena itu perlu penanganan yang lebih baik dari sistem tataniaga komoditi ini. Sistem pemasaran yang baik akan memberikan keuntungan yang besar pada petani khususnya petani karet rakyat sehinga akan merangsang para petani untuk meningatkan produksinya baik dilihat dari segi kualitas maupun kuantitasnya, suatu kegiatan tataniaga dikatakan efisien apabila kegiatan ini dapat memberikan balas jasa yang seimbang kepada semua pihak yang terlibat, yaitu produsen, pedagang dan konsumen akhir (Azzaino, 2008).

Efisiensi tataniaga secara umum dapat dibedakan atas efisiensi operasional dan efisiensi harga. Efektifitas mengacu kepada bagaimana tujuan distribusi dapat diselesaikan dengan baik, sedangkan efisiensi mengacu kepada penyelesaian tugas pendistribusian dengan sumber daya yang sekecilkecilnya.

Harga karet yang ada di desa Sumbu Sari pada Bulan juni tahun 2018 yaitu Rp 7.000 sampai Rp 8.000 per kilogram untuk harga di tingkat petani, sedangkan harga di tingkat pedagang pengumpul sampai ke pabrik yaitu Rp 10.000 lebih per kilogramnya. Peluang lain yang dapat memperbaiki penerimaan petani karet di Desa Sumbu Sari Kecamatan Mesuji Raya Kabupaten Ogan Komering Ilir adalah perilaku industri yang selalu berupaya meningkatkan efisiensi proses produksi yang dilakukan oleh industri karet serta penghargaan terhadap mutu yang semakin meningkat. Industri karet pada dasarnya lebih menghendaki bahan baku bokar yang berkualitas baik sebab dengan demikian perusahaan akan dapat mengurangi biaya produksi pada gilirannya juga diharapkan dapat berdampak pada kenaikan harga karet di tingkat petani. 
Berdasarkan latar belakang, di atas merasa tertarik untuk melakukan penelitian yang berjudul : Analisis Efisiensi Tataniaga Bahan Olah Karet (BOKAR) di Desa Sumbu Sari Kecamatan Mesuji Raya Kabupaten Ogan Komering Ilir.

\section{B. Rumusan Masalah}

Berdasarkan latar belakang di atas maka dirumusan permasalah penelitian sebagai berikut :

1. Bagaimana saluran tataniaga bahan olah karet (BOKAR) di Desa Sumbu Sari Kecamatan Mesuji Raya Kabupaten Ogan Komering Ilir?

2. Berapa besar tingkat efisiensi tataniaga bahan olah karet (BOKAR) di Desa Sumbu Sari di lihat dari Marjin tataniaga, keuntungan tataniaga dan bagian yang diterima petani ?

\section{Tujuan Penelitian}

Berdasarkan latar belakang dan rumusan masalah, adapun Tujuan dari penelitian ini adalah sebagai berikut :

1. Mengetahui bagaimana saluran tataniaga bahan olah karet (BOKAR) di Desa Sumbu Sari Kecamatan Mesuji Raya Kabupaten Ogan Komering Ilir.

2. Menghitung berapa besar tingkat efisiensi tataniaga bahan olah karet (BOKAR) di Desa Sumbu Sari dilihat dari Marjin tataniaga, keuntungan tataniaga dan bagian yang diterima petani.

\section{Kegunaan Penelitian}

Hasil penelitian ini diharapkan dapat berguna di masa yang akan datang, antara lain :

1. Memberikan gambaran kepada pihak-pihak yang terkait dalam tataniaga bahan olah karet (bokar) di Desa Sumbu Sari Kecamatan Mesuji Raya Kabupaten Ogan Komering Ilir.

2. Bermanfaat sebagai informasi dan pengetahuan bagi yang membutuhkan dapat menjadi bahan acuan untuk penelitian selanjutnya.

\section{METODOLOGI PENELITIAN}

\section{A. Ruang Lingkup Penelitian}

Penelitian ini dilaksanakan di Desa Sumbu Sari Kecamatan Mesuji Raya Kabupaten Ogan Komering Ilir. Lokasi Penelitian ini ditentukan secara sengaja (purposive) dengan pertimbangan karena Desa Sumbu Sari Kecamatan Mesuji Raya Kabupaten Ogan Komering Ilir merupakan Desa atau daerah pengembangan pertanian khususnya perkebunan karet, jumlah petani karet yang ada di sana sebanyak 100 kepala keluarga. Waktu penelitian ini dilakukan selama satu bulan.

\section{B. Metode Penelitian}

Metode yang digunakan dalam penelitian ini adalah Metode Survey. Penggunaan metode ini dimaksudkan untuk mengadakan pengamatan secara langsung untuk memperoleh keterangan secara faktual dari daerah contoh yang diteliti dengan cara melakukan penarikan sampel untuk mewakili populasi dan mengumpulkan data.

\section{Metode Pengambilan Sampel}

Metode pengambilan sampel yang digunakan adalah acak sederhana (Random sampling). Pengambilan sampel dilakukan terhadap petani karet yang tanaman karetnya berumur sekitar 10 sampai 15 tahun dengan luas 
lahan rata-rata 2 ha dan jumlah populasi yaitu 100 kepala keluarga petani karet di Desa Sumbu Sari. Sementara sampel yang di ambil 20 persen, jadi jumah petani sampel adalah 20 orang petani karet sebagai responden.

\section{Metode Pengumpulan Data}

Data yang diambil terdiri dari data primer dan data sekunder. Data primer didapatkan dari hasil pengamatan dan wawancara langsung kepada petani karet dan pedagang contoh menggunakan kuisioner. Data sekunder diambil dari instansi terkait yang ada hubungannya dengan penelitian ini.

\section{E. Metode Pengolahan Data}

Untuk menjawab rumusan permasalahan pertama mengenai bagaimana saluran tataniaga bahan olah karet (bokar) di Desa Sumbu Sari Kecamatan Mesuji Raya Kabupaten Ogan Komering Ilir menggunakan metode analisis deskriptif dengan mengumpulkan informasi dan wawancara langsung dengan petani karet.

Untuk menjawab rumusan permasalahan yang kedua digunakan sebagai berikut :
1. Untuk menghitung marjin tataniaga, soekartawi (2002), digunakan rumus :$$
\mathrm{MT}=\mathrm{HK}-\mathrm{HP}
$$

Keterangan :

$\mathrm{MT}=$ Marjin total tataniaga $(\mathrm{Rp} / \mathrm{kg})$

$\mathrm{HK}=$ Harga tingkat konsumen $(\mathrm{Rp} / \mathrm{kg})$

$\mathrm{HP}=$ Harga tingkat produsen $(\mathrm{Rp} / \mathrm{kg})$
2. Untuk menghitung keuntungan pada masing lembaga tataniaga, soekartawi (2002) digunakan rumus :

$$
\mathrm{Kti}=\mathrm{Hji}-\mathrm{Bti}
$$

Keterangan :

Kti = Keuntungan tataniaga ke- $\mathrm{i}$ $(\mathrm{Rp} / \mathrm{kg})$

$\mathrm{Hji}=$ Harga jual produk ke-i $(\mathrm{Rp} / \mathrm{kg})$

Bti = Biaya tataniaga ke-i $(\mathrm{Rp} / \mathrm{kg})$

3. Untuk menghitung farmer's share pada masing-masing lembaga tataniaga (Beta, 2007), digunakan rumus :

$\mathrm{FS}=\mathrm{HP} / \mathrm{HK} \times 100 \%$

Keterangan :

FS = Farmer's share (\%)

$\mathrm{HP}=$ Harga di tingkat produsen $(\mathrm{Rp} / \mathrm{kg})$

$\mathrm{HK}=$ Harga ditingkat konsumen $(\mathrm{Rp} / \mathrm{kg})$

4. Untuk Melihat efisiensi saluran tataniaga digunakan rumus :

$$
\mathrm{ET}=\frac{T B T}{T N P} \times 100 \%
$$

Keterangan :

ET = Efisiensi tataniaga (\%)

TBT $=$ Total biaya tataniaga $(\mathrm{Rp} / \mathrm{Kg})$

$\mathrm{TNP}=$ Total nilai produk $(\mathrm{Rp} / \mathrm{Kg})$

Kriteria efisiensi lembaga tataniaga, yaitu :

- ET sebesar 0\% - 50\% maka saluran tataniaga efisien

- ET lebih besar dari 50\% maka saluran kurang efisien 


\section{HASIL DAN PEMBAHASAN}

\section{A.Keadaan Umum Lokasi Penelitian}

\section{Lokasi dan Batas Wilayah}

Adapun Batas-batas wilayah

Desa Sumbu Sari adalah sebagai berikut :

a) Sebelah Utara: Desa Suka Sari

b) Sebelah Selatan:Desa Sumber Baru

c) Sebelah Timur:Desa Kemang Indah

d) Sebelah Barat: Desa Cipta Sari

\section{Keadaan Penduduk dan Mata}

Pencaharian

Penduduk Desa Sumbu Sari pada umumnya adalah masyarakat pendatang yang berasal dari pulau Jawa. Mereka adalah penduduk trasmigrasi yang telah menempati Desa Sumbu Sari sejak 1982 tahun.

Penghasilan utama mayoritas penduduk Desa Sumbu Sari adalah sektor perkebunan (kelapa sawit dan karet).

\section{Sarana dan Prasarana \\ a. Pendidikan}

Sarana pendidikan di Desa Sumbu Sari Kecamatan Mesuji Raya Kabupaten Ogan Komering Ilir sudah tergolong cukup maju, karena di Desa Sumbu Sari Kecamatan Mesuji Raya Kabupaten Ogan Komering ilir terdapat sarana pendidikan seperti Taman Kanakkanak (TK/PAUD), Sekolah Dasar (SD/MI), sedangkan Sekolah Menengah Pertama (SMP/MTS) ada di Desa Sumbu Sari Kecamatan Mesuji Raya Kabupaten Ogan Komering Ilir dan Sekolah Menengah Atas (SMA) berada di Desa Sumbu Sari Kecamatan Mesuji
Raya Kabupaten Ogan Komering Ilir.

\section{b. Kesehatan}

Sarana kesehatan sudah tersedia di Desa Sumbu Sari Kecamatan Mesuji Raya Kabupaten Ogan Komering Ilir yaitu sudah tersedianya sarana kesehatan seperti Puskesmas Pembantu (PUSTU) yang terdiri 1 unit dan klinik yang terdiri 2 unit, sedangkan keperluan air bersih diperoleh dari sumur dan penampungan air.

\section{c. Tempat Ibadah}

Sarana ibadah di Desa Sumbu

Sari Kecamatan Mesuji Raya Kabupaten Ogan Komering Ilir terdiri dari 1 unit masjid, 18 unit mushola dan 1 unit gereja yang digunakan penduduk untuk melaksanakan kewajibannya sebagai umat beragama dan untuk kegiatan lainya.

\section{d. Komunikasi}

Sarana komunikasi di Desa Sumbu Sari Kecamatan Mesuji Raya Kabupaten Ogan Komering Ilir antar lain Televisi (TV), Tape, Radio, untuk komunikasi jarak jauh dapat dilakukan dengan memgunakan telepon genggam atau handphone (HP).

\section{B. Identitas Petani Contoh}

Berdasarkan hasil penelitian terhadap petani karet di Desa Sumbu Sari kecamatan Mesuji Raya Kabupaten Ogan Komering Ilir, identitas petani responden dapat dilihat pada tabel 1 dan tabel 2 berikut:

Tabel 1. Usia Petani Contoh di Desa Sumbu Sari, 2018 


\begin{tabular}{llcr}
\hline No & Usia & $\begin{array}{l}\text { Jumlah } \\
\text { (Jiwa) }\end{array}$ & $\begin{array}{r}\text { Persentas } \\
\text { e (\%) }\end{array}$ \\
\hline 1 & $30>$ & & 13 \\
& 60 & & 65 \\
2 & $61>$ & 7 & 35 \\
& 70 & & 100 \\
\hline & $\begin{array}{l}\text { Jumla } \\
\text { h }\end{array}$ & 20 & \\
\hline
\end{tabular}

Sumber: Monografi Ds Sumbu Sari, 2018

Berdasarkan tabel 1 di atas, terlihat bahwa petani contoh dalam penelitian ini sebagian besar ( 65\%). Berada pada usia produktif, yaitu 30 - 60 tahun,sisanya $35 \%$. Berada pada usia kurang produktif, yaitu usia ( 60 -70 tahun).

Tabel 2. Pendidikan Petani Contoh di Desa Sumbu Sari, 2018

\begin{tabular}{|c|c|c|c|}
\hline$\overline{\text { No }}$ & $\begin{array}{l}\text { Pendidik } \\
\text { an }\end{array}$ & $\begin{array}{l}\text { Jumlah } \\
\text { (Jiwa) }\end{array}$ & $\begin{array}{r}\text { Persenta } \\
\text { se }(\%)\end{array}$ \\
\hline 1 & SD & 1 & 60 \\
\hline 2 & SMP & 4 & 20 \\
\hline 3 & SMA & 4 & 20 \\
\hline & Jumlah & 30 & 100 \\
\hline
\end{tabular}

Sumber : Kantor Desa Sumbu Sari, 2018.

Berdasarkan tabel 2 dapat dijelaskan bahwa tingkat pendidikan SD sebanyak 12 jiwa, SMP sebanyak 4 jiwa dan SMA adalah 4 jiwa.

\section{Saluran Tataniaga}

Keberhasilan lembaga tataniaga pertanian dalam mendistribusikan komoditas dari petani produsen ke konsumen akhir salah satunya dapat ditunjukkan oleh marjin tataniaga yang serendah rendahnya, (Soekartawi). Dalam penelitian ini, alur tataniaga Bahan Olah Karet (BOKAR) hingga pabrik PT. Hevea MK II di Palembang. PT. Hevea MK II dengan demikian dianggap sebagai konsumen terakhir dalam analisis tataniaga karet yang dilakukan.

Petani memiliki saluran tataniaga yang melibatkan dua lembaga perantara yaitu pedagang besar dan pabrik/eksportir (PT. Hevea MK II) sebagai konsumen akhir pada Saluran tataniaga Bahan Olah Karet (BOKAR) di Desa Sumbu Sari Kecamatan Mesuji Raya Kabupaten Ogan Komering Ilir.

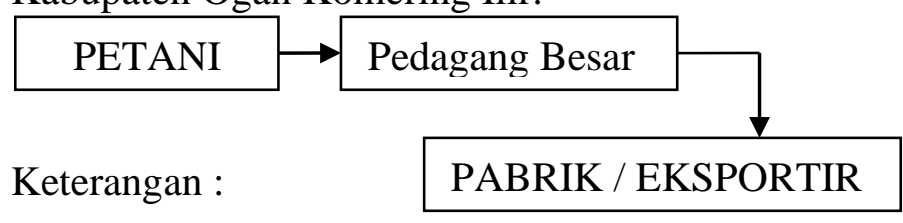

\section{$\longrightarrow \quad$ Menjual}

Gambar 2 : Saluran tataniaga bahan olah karet (Bokar) di Desa Sumbu Sari Kecamatan Mesuji Raya Kabupaten Ogan Komering Ilir.

\section{Berdasarkan gambar 2 pihak} petani menghubungi beberapa pedagang besar untuk mengetahui berapa besar harga yang akan diberikan pada saat itu kemudian harga yang paling tinggi itulah yang akan di ambil.

Tahap selanjutnya adalah penimbangan bahan olah karet (Bokar) pada masing-masing petani, nama petani yang terpanggil langsung melihat proses penimbangan . Apabila pada saat penimbangan ditemukan bahan olah karet (Bokar) yang tidak memenuhi persyaratan maka bahan olah karet (bokar) tersebut tidak akan di timbang dan akan di kembalikan 
kepada pemiliknya.

Petani karet menghasilkan bahan olah karet (BOKAR) menjual langsung kepada pedagang besar, karena petani tidak dapat menjual hasil bahan olah karet (Bokar) langsung ke pabrik/eksportir dikarenakan jarak lokasi tempat tinggal petani dengan pabrik yang jauh, sedangkan pedagang besar memiliki transportasi sehingga menjual bahan olah karet (Bokar) ke pabrik/eksportir.

\section{Analisis Efisiensi Tataniaga}

\section{Marjin Tataniaga}

Hasil analisis marjin tataniaga dapat disajikan dalam bentuk tabel 3 sebagai berikut :

\section{Tabel 3. Marjin Tataniaga}

\begin{tabular}{ll}
\hline Uraian & Nilai \\
\hline Hrg tk.Produsen $(\mathrm{Rp} / \mathrm{kg})$ & 8000 \\
Hrg Tk Konsumen $(\mathrm{Rp} / \mathrm{Kg})$ & 14000 \\
\hline Marjin Tataniaga $(\mathrm{Rp} / \mathrm{kg})$ & 6000 \\
\hline
\end{tabular}

Sumber : Diolah dari data primer, 2018

Berdasarkan tabel 3, harga yang didapat petani Bahan Olah Karet (BOKAR) sebagai produsen adalah Rp. 8.000/kg sedangkan harga yang dibayarkan konsumen akhir sebesar Rp. $14.000 / \mathrm{kg}$ bokar. Hal tersebut yang menyebabkan marjin total sebesar Rp.6000/Kg. Ini menunjukkan bahwa ada perbedaan harga tingkat produsen dan konsumen sehingga menimbulkan marjin tataniaga.

\section{Keuntungan Tataniaga}

Hasil analisis keuntungan tataniaga dapat disajikan dalam bentuk tabel 4 sebagai berikut :
Tabel 4. Keuntungan masingmasing lembaga Tataniaga

Sumber : Diolah dari data primer,

\begin{tabular}{lccc}
\hline \multirow{2}{*}{ Uraian } & \multicolumn{3}{c}{ Lembaga Tataniaga } \\
\cline { 2 - 4 } & $\begin{array}{c}\text { Petani } \\
\text { Karet }\end{array}$ & $\begin{array}{c}\text { Pedagang } \\
\text { besar }\end{array}$ & $\begin{array}{l}\text { Pabrik/ } \\
\text { Eksportir }\end{array}$ \\
\hline $\begin{array}{l}\text { Marjin Tataniaga } \\
\text { (Rp/Kg) }\end{array}$ & 8.000 & 6.000 & 8.792 \\
$\begin{array}{l}\text { Biaya Tataniaga } \\
\text { (Rp/Kg) }\end{array}$ & $2.961,79$ & $3.187,19$ & - \\
$\begin{array}{l}\text { Keuntungan } \\
\text { (Rp/Kg) }\end{array}$ & $\mathbf{5 . 0 3 8 , 2 1}$ & $\mathbf{2 . 8 1 2 , 8 1}$ & - \\
\hline 2018 & & & \\
\end{tabular}

Berdasarkan tabel 4, lembaga yang memperoleh keuntungan terbesar adalah petani yaitu Rp. 5.038,21/Kg sedangkan pendapatan pedagang besar adalah sebesar Rp. $2.812,81 / \mathrm{Kg}$.

Perbedaan tersebut dikarenakan perbedaan biaya yang dikeluarkan pada masing-masing lembaga tataniaga dalam proses tataniaga Bahan Olah Karet (BOKAR). Ini menunjukkan bahwa keuntungan yang didapat petani lebih besar dari pada pedagang besar.

\section{Farmer's Share Tataniaga}

Hasil analisis farmer's share tataniaga dapat disajikan dalam bentuk tabel 5 sebagai berikut :

Tabel 5. Farmer's Share Tataniaga

\begin{tabular}{lc}
\hline \multicolumn{1}{c}{ Uraian } & Nilai \\
\hline Harga tk produsen $(\mathrm{Rp} / \mathrm{Kg})$ & 8.000 \\
Harga tk konsumen $(\mathrm{Rp} / \mathrm{Kg})$ & 14.000 \\
\hline Farmer's share (\%) & $\mathbf{5 7 , 1 4}$ \\
\hline
\end{tabular}

Sumber : Diolah dari data primer, 2018

Berdasarkan tabel 5, harga yang didapat petani Bahan Olah Karet (BOKAR) adalah Rp. $\quad 8.000 / \mathrm{kg}$ sedangkan harga yang dibayarkan konsumen akhir sebesar Rp. $14.000 / \mathrm{kg}$. Hal tersebut yang 
menyebabkan farmer's share sebesar $57,14 \%$. Ini menunjukkan bahwa harga tingkat produsen dan harga tingkat konsumen sehingga terjadinya persentase.

\section{Efisiensi Tataniaga}

Hasil analisis Efisiensi tataniaga dapat disajikan dalam bentuk tabel 7 sebagai berikut :

Tabel 6. Efisiensi Tataniaga

\begin{tabular}{llll}
\hline & \multicolumn{3}{c}{ Lembaga Tataniaga } \\
\cline { 2 - 4 } Uraian & $\begin{array}{c}\text { Petani } \\
\text { Karet }\end{array}$ & $\begin{array}{c}\text { Pedagan } \\
\text { g besar }\end{array}$ & $\begin{array}{l}\text { Pabrik/ } \\
\text { Eksport } \\
\text { ir }\end{array}$ \\
\hline $\begin{array}{l}\text { Marjin Tataniaga } \\
\text { (Rp/Kg) }\end{array}$ & 8.000 & 6.000 & 8.792 \\
$\begin{array}{l}\text { Biaya Tataniaga } \\
\text { (Rp/Kg) }\end{array}$ & $2.961,79$ & $3.187,19$ & - \\
\hline $\begin{array}{l}\text { Keuntungan } \\
\text { (Rp/Kg) }\end{array}$ & $\mathbf{5 . 0 3 8 , 2 1}$ & $\mathbf{2 . 8 1 2 , 8 1}$ & - \\
\hline
\end{tabular}

Sumber : Diolah dari data primer, 2018

Berdasarkan tabel 6, terlihat bahwa nilai efisiensi tataniaga untuk saluran tataniaga Bahan Olah Karet (BOKAR) di Desa Sumbu Sari Kecamatan Mesuji Raya Kabupaten Ogan Komering Ilir yaitu sebesar 43,92\% (efisien). Ini menunjukkan bahwa total biaya tataniaga dan total nilai produk sehingga tingkat efisiensi tataniaga menjadi efisien.
Tabel 7. Analisis Marjin dan Efisiensi Tataniaga

\begin{tabular}{|c|c|c|c|c|}
\hline \multirow{2}{*}{$\begin{array}{l}\mathbf{N} \\
\mathbf{0}\end{array}$} & \multirow{2}{*}{ Keterangan } & \multicolumn{2}{|c|}{$\begin{array}{c}\text { Harga } \\
(\mathrm{Rp} / \mathrm{Kg})\end{array}$} & \multirow[t]{2}{*}{$(\%)$} \\
\hline & & $\begin{array}{c}\text { Jual/ } \\
\text { Beli }\end{array}$ & Biaya & \\
\hline \multirow[t]{4}{*}{1} & Petani & & & \\
\hline & Harga Jual & 8000 & & \\
\hline & Total Biaya & & & \\
\hline & Keuntungan & & & \\
\hline \multirow[t]{12}{*}{2} & Pedagang Besar & & & \\
\hline & Harga Beli & 8000 & & \\
\hline & Biaya Tataniaga & & & \\
\hline & a. Biaya & & 387,19 & 12,15 \\
\hline & Operasional & & & \\
\hline & b. Penyusutan & & 2800 & 87,85 \\
\hline & $20 \%$ & 14000 & & \\
\hline & Total Biaya & 6000 & 3187,1 & 100 \\
\hline & & & 9 & \\
\hline & Harga Jual & 14.000 & & \\
\hline & Marjin & 6.000 & & \\
\hline & Keuntungan & 2812,8 & & \\
\hline \multirow[t]{2}{*}{3} & Pabrik/Eksportir & & & \\
\hline & Harga Beli & 14000 & & \\
\hline 4 & Total Marjin & 6000 & & \\
\hline \multirow[t]{2}{*}{5} & Total & & & \\
\hline & Tataniaga & & $6.148,9$ & \\
\hline 6 & Farmer's share & & 8 & 57,14 \\
\hline \multirow[t]{2}{*}{7} & Efisiensi & & & 43,92 \\
\hline & Tataniaga & & & \\
\hline
\end{tabular}

Sumber : Diolah dari data primer, 2018

\section{a. Marjin}

Besar kecilnya nilai efisiensi tataniaga dipengaruhi oleh nilai marjin tataniaga. Semakin besar nilai marjin suatu saluran tataniaga maka semakin tidak efisiean, dan sebaliknya apabila nilai marjin suatu saluran tataniaga semakin kecil maka semakin efisien.

Berdasarkan tabel 7, Marjin tataniaga sebagai perbedaan harga atau selisih harga yang dibayar konsumen dengan harga yang diterima petani produsen atau dapat pula dinyatakan sebagai nilai dari jasa-jasa pelaksanaan kegiatan tataniaga sejak dari tingkat petani 
sampai ke titik konsumen akhir yaitu pabrik/eksportir. Untuk memindahkan bahan olah karet (bokar) dari titik produsen ke titik konsumen membutuhkan pengeluaran baik fisik maupun materi. Pengeluaran yang harus dilakukan untuk menyalurkan bahan olah karet (bokar) dari produsen ke konsumen disebut biaya tataniaga.

Dapat dilihat bahwa saluran tataniaga di Desa Sumbu Sari Kecamatan Mesuji Raya Kabupaten Ogan Komering Ilir didapat nilai total marjin tataniaga Rp.6.000/Kg,

\section{b. Keuntungan}

Keuntungan tataniaga adalah margin tataniaga dikurangi biaya tataniaga, persentase bagaian yang diterima petani terhadap harga jual diperoleh dengan membagi keuntungan dikalikan 100 persen.

Keuntungan yang diperoleh pada petani lebih besar dari pada pedaagang besar, maka keuntungan yang diperoleh petani sebesar $\mathrm{Rp}$. $5.038,21 / \mathrm{Kg}$.

\section{c. Farmer's Share}

farmer's share tataniaga merupakan perbandingan harga tingkat petani karet dengan harga di konsumen akhir dan dinyatakan persentase, bagian harga yang besar di terima oleh petani karena petani bertindak sebagai pedagang, maka farme's share yang diperoleh yaitu $57,14 \%$.

\section{d. Efisiensi}

Tingkat efisiensi tataniaga juga dapat diukur melalui besarnya rasio keuntungan terhadap biaya tataniaga. Rasio keuntungan terhadap biaya tataniaga didefinisikan sebagai besarnya keuntungan yang diterima atas biaya tataniaga yang dikeluarkan.

Untuk mengetahui efisien tidaknya tataniaga bahan olah karet (bokar) di Desa Sumbu Sari Kecamatan Mesuji Raya Kabupaten Ogan Komering Ilir, semakin meratanya penyebaran rasio keuntungan terhadap biaya maka dari segi operasional sistem tataniaga akan semakin efisien, maka efisiensi tataniaga bahan olah karet di Desa Sumbu Sari Kecamatan Mesuji Raya Kabupaten Ogan Komering Ilir yaitu 43,92\% (efisien).

\section{KESIMPULAN DAN SARAN}

\section{A. Kesimpulan}

Berdasarkan hasil penelitian dan pembahasan dapat diambil kesimpulan sebagai berikut :

1. Terdapat satu saluran tataniaga yang melibatkan dua lembaga perantara yaitu pedagang besar dan pabrik/eksportir (PT. Hevea MK II) sebagai konsumen akhir pada Saluran tataniaga Bahan Olah Karet (BOKAR) di Desa Sumbu Sari Kecamatan Mesuji Raya Kabupaten Ogan Komering Ilir.

2. Tingkat efisiensi tataniaga Bahan Olah Karet (BOKAR) yaitu sebesar 43,92\% (efisien) dengan nilai total marjin tataniaga Rp.6.000/Kg, keuntungan tataniaga sebesar Rp. 5.038,21/Kg dan farmer's share yaitu $57,14 \%$ yang terdapat pada saluran tataniaga di Desa Sumbu Sari Kecamatan Mesuji Raya Kabupaten Ogan Komering Ilir.

\section{B. Saran}


Berdasarkan hasil penelitian dan pembahasan dapat disarankan sebagai berikut :

1. Perlu adanya kerja sama petani Bahan Olah Karet (BOKAR) dengan Koperasi Unit Desa (KUD) guna menyikapi penekanan harga dan penurunan harga yang terjadi pada petani Bahan Olah Karet (BOKAR) di Desa Sumbu Sari Kecamatan Mesuji Raya Kabupaten Ogan Komering Ilir.

2. Koperasi Unit Desa (KUD) diharapkan dapat menerima hasil Bahan Olah Karet (BOKAR) dari petani dan langsung menjualnya ke pabrik/eksportir untuk memperkecil selisih marjin tataniaga, meningkatkan farmer's share tataniaga dan meningkatkan efisiensi tataniaga Bahan Olah Karet (BOKAR) di Desa Sumbu Sari Kecamatan Mesuji Raya Kabupaten Ogan Komering Ilir.

\section{DAFTAR PUSTAKA}

Azzaino, Z., 2008. Pengantar Tataniaga Pertanian. Departemen Ilmu-ilmu Sosial Ekonomi Pertanian, IPB. Bogor.

Dinas Perkebunan. 2013. Banyaknya Petani Perkebunan Rakyat Menurut Kecamatan Dan Jenis Komoditas Di Kab Ogan Komering Ilir Dinas Perkebunan Kab.Ogan Komering Ilir.

Dinas Perkebunan Kecamatan Mesuji Raya 2013. Luas Areal Perkebunan Karet Pola Swadaya Perdesa Di Kecamatan Mesuji Raya Kabupaten Ogan Komering
Ilir. Dinas Perkebunan Kabupaten Ogan Komering Ilir.

Husin, S. 2009. Analisis FaktorFaktor Yang Mempengaruhi Produktivitas Usahatani dan Pengaruhnya Terhadap Kepuasan Petani (Studi Kasus Bumdes Pt Agropotombuluh Di Kecamatan Telaga Biru Kabupaten Gorontalo). Tesis. Fakultas Ekonomi. Program Magister Perencanaan dan Kebijakan Publik. Universitas Indonesia. Jakarta.

Idrus, 2010. Analisis pemasaran karet di kabupaten musi rawas sumatra selatan.

Mubyarto dan Dewantara, A.S., 2008. Karet Kajian Sosial Ekonomi. Adytia Media. Yogyakarta.

Nancy, C.,2008. Usaha Untuk Meningkatkan Daya Saing Karet Alam Indonesia di Pasar Internasional Melalui Efisiensi Pemasaran. Tesis. Fakultas Pascasarjana IPB. Bogor.

Marpaung, K. Iksan S. Kiptiyah S.M., 2009. Analisis Pemasaran Karet Rakyat dalam Upaya Meningkatkan Harga di Tingkat Petani. Studi Kasus pada Sentra Produksi di Kecamatan Kumai. Kalimantan Tengah. Jurnal Penelitian Ilmu-ilmu Sosial PPS Universitas Brawijaya Malang I (02): 127140.

Napitupulu, D.M.T., 2004. Model 
Perdagangan Karet Alam Indonesia. Simulasi Kebijakan Menghadapi Kesepakatan Tripartite dan Perdagangan Bebas. Disertasi. Program Pascasarjana Universitas Brawijaya. Malang.

Ningsih, Fitria. 2013. Skripsi Analisis Saluran Pemasaran Dan Transmisi Harga Karet Pada Petani Swadaya Di Desa Sawah. Kecamatan Kampar Utara Kabupaten Kampar. Program Studi Agribisnis Fakultas Pertanian. Pekanbaru Universitas Riau.

Pranata 2009. Analisis efisiensi tataniaga bahan olah karet (Bokar) di Kabupaten Tanggamus.

Puspandari 2009. Analisis efisiensi tataniaga bahan olah karet (Bokar) di Kecamatan Bandar Sribhawono Kabupaten Lampung Timur.

Ratnadani.

https://ratnadanie.wordpress.com/ matek-tc/

Renaldi. 2011. Analisis Pemasaran Karet (Havea Brasiliensis)di Desa Batubelah Kecamatan Kampar Kabupaten Kampar. Universitas Riau, Pekanbaru (tidak dipublikasikan).

Soekartawi. 2009. Agribisnis Teori dan Aplikasi. PT Raja Grafindo Persada.

Sudiyono, Armand, 2008. Pemasaran Pertanian. UMM Press. Malang.
Swastha, Basu dan Irawan, 2008. Manajemen Pemasaran: Analisa Perilaku Konsumen. BPFE. Yogyakarta.

Yupin, A.D, Ismail M. dan Ananda C.F. 2013. Analisis Pemasaran Karet di Kabupaten Kapuas. WACANA 12(3): 519-538. Universitas Indonesia. Jakarta. 
